\title{
What factors do critical access hospital trustee/board members believe are important to recruitment of physicians and do they differ from hospital administrators and physicians
}

\author{
Edward Trusdale Baker*1, David Schmitz ${ }^{2}$, Jessica Marshall ${ }^{1}$, Lisa MacKenzie ${ }^{1}$ \\ ${ }^{1}$ Center for Health Policy, College of Health Sciences, Boise State University, United States \\ ${ }^{2}$ Family and Community Medicine, University of North Dakota School of Medicine and Health Sciences, United States
}

Received: March 30, 2017

DOI: $10.5430 /$ jha.v6n3p33
Accepted: April 23, 2017

Online Published: May 3, 2017

\begin{abstract}
Background: Rural hospitals continue to struggle to recruit physicians. Examining trustee/board member perceptions of their community's strengths and challenges related to physician recruitment may provide insight on how to sustain an effective workforce in these facilities.

Objective: The purpose of this study is to identify similarities and differences between critical access hospital (CAH) trustee/board members' perspectives on factors important to physician recruitment compared to their hospital administrators and physicians practicing in their facilities.

Methods: The CAH Community Apgar Questionnaire (CAH CAQ) was expanded to include trustee/board member participation in Iowa. Online survey methods were used to compile information from trustees/board members, hospital administrators and physician from participating CAHs recruited by the Iowa Hospital Association.

Results: A total of 16 Iowa CAH communities participated in the project in 2015. There were 17 administrators, 39 physicians and 23 board members respondents for a total of 79 respondents. Significant differences were found between trustee/board members and hospital administrators ratings on CAH CAQ factors loan repayment and transfer arrangements. Trustee/board members and physicians showed significant differences on scores for the CAH CAQ class factor hospital/community support and on factor ratings for teaching, administration, hospital sponsored continuing medical education and welcome and recruitment programs.

Discussion: This study has identified commonalities and differences in how rural hospital trustee/board members and the administrators and physicians who work at their facilities view community strengths related to physician recruitment. Analyzing and discussing the areas of consensus and differences of opinion could help develop more effective physician recruitment strategies for these communities.
\end{abstract}

Key Words: Rural hospital trustee/board member, Rural physician recruitment, Critical access hospital workforce

\footnotetext{
*Correspondence: Edward Trusdale Baker; Email: ebaker@boisestate.edu; Address: Center for Health Policy, College of Health Sciences, Boise State University, United States.
} 


\section{INTRODUCTION}

The United States has a nationwide shortage of physicians which is only expected to worsen. ${ }^{[1]}$ It is important to examine ways to recruit physicians to rural areas that are often already experiencing a shortage. It is estimated that by the year 2030, there will be a shortage of 30,000 surgeons and 20,400 primary care physicians by $2020,{ }^{[2,3]}$ with $95 \%$ of the shortages occurring in nonmetropolitan areas. ${ }^{[4]}$ These rural areas must fill the gaps in healthcare services unique to being in an isolated environment. Research suggests hospital trustee/board members have increasing responsibility to recruit physicians to their communities as they have the ability to impact rural health through guidance in workforce initiatives that integrate providers within the community. ${ }^{[5]}$

Hospital trustee/board members' general role involves strategic planning and priority goal setting. ${ }^{[6]}$ As changing healthcare legislation requires increased focus on safety and quality of care, trustee/board members must adapt their governing policies to fit this dynamic healthcare environment. ${ }^{[7]} \mathrm{Col}-$ laboration between medical professionals and trustee/board members can lead to an increased understanding of board dynamics for clinical providers, leading to reduced conflict and a more positive working environment; this in turn can lead to better safety and quality of care. ${ }^{[7]}$ Trustee/board members have the responsibility to not only monitor their organization but to be engaged with strategic decision making to address priority needs. ${ }^{[8]}$ Trustee/board members are increasingly accountable for the hospital's quality, safety, and financial performance, and those with more effective management practices also have higher quality scores. ${ }^{[6,9]}$

In the past, boards rarely consulted and utilized the physicians employed with the hospital but are now working to strengthen the physician-hospital relationship. Hospital trustee/board members are encouraged to include culturally diverse members as well as an array of professional experience to provide a range of expertise on the board. ${ }^{[8,10]}$ The Joint Commission on Accreditation of Healthcare Organizations encourages trustee/board members to include physician board members. ${ }^{[11]} \mathrm{A}$ recent study suggests physician members on the trustee/board are an asset for clinical integration. ${ }^{[12]}$ Experienced physician representation on hospital boards is a way to further increase the working relationship between administrative and clinical aspects of a hospital and decrease potential personnel conflicts. ${ }^{[12,13]}$ Physician representation on the board adds diversity and increases communication between medical professionals and trustee/board members. ${ }^{[10,14]}$

While not all trustee/board members will appoint physician members, many are utilizing physician insight with decision making. Research shows that physicians that are content with their hospital board dynamics are more likely to remain at the facility. ${ }^{[15]}$ Engaging hospital physicians and trustee/board members is one way to find solutions to issues such as hospital operating losses. ${ }^{[13]}$ A positive trustee/board member and physician facility culture can provide a powerful recruiting tool for physicians who are experienced in administrative and governing roles which in turn can allow for increased diversity on the board. ${ }^{[8,11,14]}$ Furthermore, a physician retention strategy can be facilitated when physicians are included in long-term clinical and operational priorities of the hospital. $^{[13,15]}$

Rural hospital trustee/board members face a unique set of challenges in regards to physician recruitment. They are often tasked with selling the community and working to integrate the physician to the community once they begin providing healthcare. ${ }^{[16]}$ It has been found that recruitment of physicians in rural areas is affected by multiple factors which have been examined across five classes including geographic, economic, scope of practices, medical support, and hospital/community support among physicians, medical students and administrator perspectives. ${ }^{[17-20]}$ However, little is known concerning rural hospital trustee/board member perspectives of factors that are influential in the recruitment of physicians to their facilities and whether these trustee/board member perspectives are consistent with their physicians and administrations.

The Critical Access Hospital Community Apgar Questionnaire (CAH CAQ) was utilized in this study to assess Iowa communities' strengths and challenges across 50 factors seen as most important from the board/trustee perspective compared to administrators and physicians. ${ }^{[19]}$ This assessment allowed for identification of factors that are most important for a community to address with limited available resources. The CAH CAQ may have a role in helping Iowa communities with self-evaluation, prioritization of improvement plans, advertising considerations and negotiation strategies for successful recruitment of physicians. Expanding this study to include trustee/board members aims to broaden the scope of physician recruitment due to the important role that trustee/board members have with the sustainability of rural health care facilities and quality of care.

The purpose of this study is to identify similarities and differences between CAH trustee/board members' perspectives on factors important to physician recruitment as compared to their hospital administrators and physicians practicing in their facilities. This study uses the Community Apgar classes and factors that identify and measure the assets and capabilities related to physician recruitment across Iowa rural communities. This study may help gain some perspective on 
how Iowa trustee/board members conceptualize physician recruitment issues and how they could participate more fully in establishing a more effective healthcare workforce for their communities.

\section{Methods}

\subsection{Human subjects review and approval}

This research project was approved by the institutional review board of the corresponding author.

\subsection{Selection and recruitment of Iowa CAH communi- ties}

A total of 16 Iowa CAH communities recruited by the Iowa Hospital Association participated in the project which began in August of 2015 and continued through March of 2016. Iowa has 82 CAHs of which $16(19.5 \%)$ participated in this study. Respondents for the Iowa CAH CAP were: (1) administrators, (2) physician leaders and (3) trustee/board members. There were $17 \mathrm{CAH}$ administrators, $39 \mathrm{CAH}$ physicians and 23 trustee/board member respondents for a total of 79 respondents.

\subsection{Survey administration process}

Target respondents were reached via electronic methods including email and an online survey which was created with the Qualtrics survey platform from September of 2015 through December of 2015. The target sample was emailed the CAH CAQ consent form and this consent form was returned to the Center for Health Policy (CHP) at Boise State University prior to receiving any research materials. Once the consent form was received the participant was then sent online educational material and a link to the Qualtrics online survey. The educational information was created in partnership with 3RNet's technical support to describe the Community Apgar factors. The 3RNet online tool was accessed roughly 140 times during this study which suggests that survey respondents used this $3 \mathrm{RNet}$ resource and consequently were more likely to evaluate the factors in a consistent manner.

\section{Results}

A full explanation of the analytics utilized in the Community Apgar Program is detailed in the Schmitz, Baker, Nukui \& Epperly's paper. ${ }^{[19]}$ In general, algorithms are created that produce a community asset and capability measure derived from a community advantage/challenge score weighted by an importance metric. Mean Community Apgar scores were calculated for the 50 factors and five classes of the CAH CAQ and descriptive and inferential statistics including nonparametric independent samples Mann-Whitney $U$ Test were employed. These analyses are discussed below by class and across class factors.

\subsection{Overall top 10 Community Apgar factors}

Table 1 includes a list of the top 10 Community Apgar factors for trustee/board members, administrators and physicians. Trustee/board members, administrators and physicians agreed on three of the top 10 factors (hospital leadership, emergency medical services, schools). Trustee/board members and administrators agreed on an additional three top 10 factors (ancillary staff workforce, perception of quality, community need/support of physician) while trustee/board members and physicians agreed on an additional two top 10 factors (transfer arrangements, endoscopy services). Trustee/board members identified two top 10 factors not identified by either administrators or physicians (administration, internet access).

\subsection{Trustee/board member vs. hospital administrator}

\subsubsection{Community Apgar classes}

Table 2 includes the cumulative class mean score comparison of trustee/board members and administrators. There were no significant results comparing trustee/board members and administrators. Trustee/board members have higher scores for the geographic, scope of practice, and hospital/community support classes while administrators have higher scores in the economic and medical support class.

Table 1. Top 10 Community Apgar factors

\begin{tabular}{|c|c|c|}
\hline Trustee/Board Member & Administrator & Physician \\
\hline Hospital leadership ${ }^{\xi}$ & Perception of quality ${ }^{z}$ & Schools $^{\xi}$ \\
\hline Emergency medical services ${ }^{\xi}$ & Emergency room coverage & Hospital Leadership ${ }^{\xi}$ \\
\hline Transfer arrangements ${ }^{\epsilon}$ & Schools ${ }^{\xi}$ & Income guarantee \\
\hline Ancillary staff workforce ${ }^{z}$ & Community need/support of physician ${ }^{z}$ & Mid-level provider workforce \\
\hline Administration $^{\S}$ & Loan repayment & Emergency medical services ${ }^{\xi}$ \\
\hline Schools $^{\xi}$ & Ancillary staff workforce ${ }^{z}$ & Revenue flow \\
\hline Perception of quality ${ }^{z}$ & Hospital leadership ${ }^{\xi}$ & Emergency room coverage \\
\hline Internet access ${ }^{\S}$ & Income guarantee & Transfer arrangements ${ }^{\epsilon}$ \\
\hline Community need/support of physician ${ }^{z}$ & Mid-level provider workforce & Start-up/marketing costs \\
\hline Endoscopy/surgery ${ }^{e^{1}}$ & Emergency medical services ${ }^{\xi}$ & Endoscopy/surgery ${ }^{\epsilon}$ \\
\hline
\end{tabular}

Note. ${ }^{\xi}$ Indicates agreement between trustee/board members, administrators and physicians; ${ }^{\not}$ Indicates agreement between trustee/board members and administrators; ${ }^{\epsilon}$ Indicates agreement between trustee/board members and physicians; ${ }^{\S}$ Only identified by trustee/board members 


\subsubsection{Community Apgar factors}

Table 3 includes the trustee/board member Community Apgar scores compared to administrators. These scores are separated by each community class category including geographic, economic, scope of practice, medical support, and hospital/community support factors. The economic class factor, loan repayment $(p=.007)$ have a significant difference between trustee/board members and administrators with administrators having a higher mean score. The medical support class factor, transfer arrangements $(p=.048)$ resulted in a significantly higher Community Apgar mean score for trustee/board members.

Table 2. Trustee/board member vs. administrator Community Apgar class scores

\begin{tabular}{lllc}
\hline Class & Mean Score & Mean Score & $p$-value \\
\hline Geographic & 14.304 & 12.235 & .787 \\
Economic & 19.783 & 30.882 & .156 \\
Scope of Practice & 25.870 & 24.824 & .871 \\
Medical Support & 30.696 & 35.177 & .626 \\
Hospital/Community Support & 35.391 & 30.882 & .498 \\
\hline
\end{tabular}

Note. ${ }^{* *} p<.01,{ }^{*} p<.05$, Mann-Whitney $U$ Test

Table 3. Trustee/board member vs. administrator Community Apgar factor scores

\begin{tabular}{|c|c|c|c|}
\hline & Mean Score & Mean Score & $p$-value \\
\hline \multicolumn{4}{|l|}{ Geographic Factors } \\
\hline - Access to larger community & 0.040 & 0.290 & 914 \\
\hline - Demographics/patient mix & -1.090 & 0.290 & 211 \\
\hline - Social networking & 2.830 & 2.180 & .588 \\
\hline - Recreational opportunities & 3.220 & 2.820 & .588 \\
\hline - Spousal satisfaction (education, work, general) & -1.740 & -2.240 & .745 \\
\hline - Schools & 4.960 & 5.710 & .935 \\
\hline - Shopping and other services & 0.300 & 0.350 & .766 \\
\hline - Religious/cultural opportunities & 2.870 & 0.940 & .120 \\
\hline - Climate & -1.300 & -1.120 & .766 \\
\hline - Perception of community & 4.220 & 3.000 & .342 \\
\hline \multicolumn{4}{|l|}{ Economic Factors } \\
\hline - Employment Status & 1.826 & 3.294 & .242 \\
\hline - Part-time opportunities & 1.174 & 0.235 & .481 \\
\hline - Loan repayment & 2.522 & 5.294 & $.007^{* *}$ \\
\hline - Income guarantee & 2.870 & 5.118 & 071 \\
\hline - Signing bonus & 1.478 & 2.529 & 607 \\
\hline - Moving allowance & 2.870 & 3.000 & .745 \\
\hline - Start-up/marketing costs & 4.000 & 3.824 & .914 \\
\hline - Revenue flow & 1.304 & 2.824 & .570 \\
\hline - Payor mix & -1.174 & 1.294 & .075 \\
\hline - Competition & 2.913 & 3.471 & .766 \\
\hline \multicolumn{4}{|l|}{ Scope of Practice Factors } \\
\hline - Obstetrics & 2.870 & 3.353 & 665 \\
\hline - C-section & 2.435 & 2.882 & .808 \\
\hline - Emergency room coverage & 3.783 & 5.765 & .342 \\
\hline - Endoscopy/surgery & 4.348 & 3.471 & .329 \\
\hline - Nursing home & 2.957 & 2.471 & .356 \\
\hline - Inpatient care & 4.261 & 4.529 & .829 \\
\hline - Mental health & -2.565 & -2.412 & 914 \\
\hline - Mid-level supervision & 3.435 & 1.529 & .066 \\
\hline - Teaching & -0.609 & 0.412 & .265 \\
\hline - Administration & 4.957 & 2.824 & .066 \\
\hline \multicolumn{4}{|l|}{ Medical Support Factors } \\
\hline - Perception of quality & 4.739 & 6.059 & .551 \\
\hline - Stability of physician workforce & 2.435 & 3.412 & .978 \\
\hline - Specialist availability & 3.435 & 2.765 & .329 \\
\hline - Transfer arrangements & 5.217 & 3.765 & $.048^{*}$ \\
\hline - Nursing workforce & 2.304 & 3.471 & .914 \\
\hline - Allied mental health workforce & -1.652 & -1.294 & .745 \\
\hline - Mid-level provider workforce & 3.783 & 4.824 & .957 \\
\hline - Ancillary staff workforce & 5.044 & 5.235 & .386 \\
\hline - Emergency medical services & 5.522 & 4.706 & 191 \\
\hline - Call/practice coverage & -0.130 & 2.235 & .356 \\
\hline \multicolumn{4}{|l|}{ Hospital and Community Support Factors } \\
\hline - Physical plant/equipment & 3.478 & 4.471 & 645 \\
\hline - Plans for capital investment & 3.174 & 2.941 & 401 \\
\hline - Electronic medical records & 2.478 & 0.471 & .416 \\
\hline - Hospital leadership & 5.826 & 5.118 & 232 \\
\hline - Internet access & 4.565 & 4.353 & .516 \\
\hline - Televideo support & 2.478 & 1.294 & .386 \\
\hline - Hospital sponsored CME & 1.783 & 2.529 & .498 \\
\hline - Community need/support of physician & 4.522 & 5.353 & .808 \\
\hline - Community volunteer opportunities & 3.348 & 2.647 & .265 \\
\hline - Welcome and recruitment program & 3.739 & 1.706 & .113 \\
\hline
\end{tabular}

Note. ${ }^{* *} p<.01,{ }^{*} p<.05$, Mann-Whitney $U$ Test 


\subsection{Trustee/board member vs. hospital physician 3.3.1 Community Apgar classes}

Table 4 includes the Community Apgar cumulative class mean score comparison of trustee/board members and physicians. Trustee/board members have higher mean scores for the geographic, scope of practice, medical support, and hospital/community support classes while physicians have higher scores in the economic class. The hospital/community support class $(p=.036)$ indicates a significant difference between trustee/board members and physicians with trustee/board members having higher mean scores.

Table 4. Trustee/board member vs. physician Community Apgar class scores

\begin{tabular}{lllc}
\hline Class & Mean Score & Mean Score & $\boldsymbol{p}$-value \\
\hline Geographic & 14.304 & 13.205 & .942 \\
Economic & 19.783 & 27.897 & .274 \\
Scope of Practice & 25.870 & 19.539 & .444 \\
Medical Support & 30.696 & 25.103 & .410 \\
Hospital/Community Support & 35.391 & 21.718 & $.036^{*}$ \\
\hline
\end{tabular}

Note. ${ }^{* *} p<.01,{ }^{*} p<.05$, Mann-Whitney $U$ Test

Table 5. Trustee/board member vs. physician Community Apgar factor scores

\begin{tabular}{|c|c|c|c|}
\hline & Mean Score & Mean Score & $p$-value \\
\hline \multicolumn{4}{|l|}{ Geographic Factors } \\
\hline - Access to larger community & 0.040 & -0.440 & .605 \\
\hline - Demographics/patient mix & -1.090 & 1.030 & .053 \\
\hline - Social networking & 2.830 & 2.410 & .566 \\
\hline - Recreational opportunities & 3.220 & 3.030 & .614 \\
\hline - Spousal satisfaction (education, work, general) & -1.740 & 0.000 & .242 \\
\hline - Schools & 4.960 & 4.970 & .910 \\
\hline - Shopping and other services & 0.300 & -0.850 & .357 \\
\hline - Climate & -1.300 & -0.920 & .354 \\
\hline - Perception of community & 4.220 & 2.640 & .161 \\
\hline \multicolumn{4}{|l|}{ Economic Factors } \\
\hline - Employment Status & 1.826 & 1.692 & .877 \\
\hline - Part-time opportunities & 1.174 & 1.513 & .626 \\
\hline - Loan repayment & 2.522 & 3.180 & .392 \\
\hline - Income guarantee & 2.870 & 4.615 & .131 \\
\hline - Signing bonus & 1.478 & 2.744 & .416 \\
\hline - Revenue flow & 1.304 & 4.128 & .065 \\
\hline - Payor mix & -1.174 & 0.256 & .179 \\
\hline - Competition & 2.913 & 2.692 & .988 \\
\hline \multicolumn{4}{|l|}{ Scope of Practice Factors } \\
\hline - Obstetrics & 2.870 & 1.897 & .340 \\
\hline - C-section & 2.435 & 1.641 & .565 \\
\hline - Emergency room coverage & 3.783 & 4.026 & .939 \\
\hline - Endoscopy/surgery & 4.348 & 3.641 & .352 \\
\hline - Nursing home & 2.957 & 2.718 & .620 \\
\hline - Inpatient care & 4.261 & 2.718 & .258 \\
\hline - Mental health & -2.565 & -3.103 & .929 \\
\hline - Mid-level supervision & 3.435 & 1.974 & .097 \\
\hline - Teaching & -0.609 & 0.897 & $.035^{*}$ \\
\hline - Administration & 4.957 & 3.128 & $.048^{*}$ \\
\hline \multicolumn{4}{|l|}{ Medical Support Factors } \\
\hline - Perception of quality & 4.739 & 3.590 & .321 \\
\hline - Stability of physician workforce & 2.435 & 1.872 & .764 \\
\hline - Nursing workforce & 2.304 & 0.974 & .343 \\
\hline - Allied mental health workforce & -1.652 & -0.846 & .497 \\
\hline - Mid-level provider workforce & 3.783 & 4.282 & .897 \\
\hline - Ancillary staff workforce & 5.044 & 3.590 & .099 \\
\hline - Emergency medical services & 5.522 & 4.231 & .118 \\
\hline - Call/practice coverage & -0.130 & 1.051 & .559 \\
\hline \multicolumn{4}{|l|}{ Hospital and Community Support Factors } \\
\hline - Physical plant/equipment & 3.478 & 3.385 & .697 \\
\hline - Plans for capital investment & 3.174 & 2.385 & .300 \\
\hline - Electronic medical records & 2.478 & 0.539 & .208 \\
\hline - Hospital leadership & 5.826 & 4.744 & .427 \\
\hline - Internet access & 4.565 & 2.539 & .057 \\
\hline - Televideo support & 2.478 & 1.103 & .251 \\
\hline - Hospital sponsored CME & 1.783 & -0.667 & $.031^{*}$ \\
\hline - Community need/support of physician & 4.522 & 3.154 & .107 \\
\hline - Community volunteer opportunities & 3.348 & 2.974 & .572 \\
\hline - Welcome and recruitment program & 3.739 & 1.564 & $.032^{*}$ \\
\hline
\end{tabular}

Note. ${ }^{* *} p<.01,{ }^{*} p<.05$, Mann-Whitney $U$ Test 


\subsubsection{Community Apgar factors}

Table 5 includes the trustee/board member Community Apgar scores compared to physicians. These scores are separated by each community class category including geographic, economic, scope of practice, medical support, and hospital/community support factors. The scope of practice class factors, teaching $(p=.035)$ and administration $(p=.048)$ indicate a significant difference between trustee/board members and physicians. Trustee/board members have a higher mean score for the administration factor and a lower mean score for the teaching factor compared to physicians. The hospital/community support class factor, hospital sponsored CME $(p=.031)$ have a significantly higher Community Apgar mean score for trustee/board members. In addition, welcome and recruitment program $(p=.032)$ have a higher Community Apgar mean score for trustee/board members.

\section{Discussion}

\subsection{Research limitations}

A limitation of this study is that the findings may not generalize to other Iowa $\mathrm{CAH}$ or to other CAHs in similar rural environments. In addition, the Iowa CAP utilized an online data collection strategy that has not been deployed in past CAP approaches and allowed multiple responses from respondent groups. A face-to-face interaction of an interview allows for a question and answer period if necessary and the online method of sending educational materials with a survey could result in potential ambiguity for some Community Apgar factors. The educational online material supplied by 3RNet seemed to be accessed with a high frequency and this might ameliorate some of these concerns. Future research will investigate whether these research methods approaches provide the same degree of fidelity as previous methods.

\subsection{Top 10 Community Apgar factors}

There seemed to be a moderate degree of agreement on the top 10 factors associated with physician recruitment as identified by trustees/board members, administrators and physicians. Three (30\% agreement rate) of the top 10 factors identified by trustees/board members were also identified by both administrators and physicians, including the top two factors identified by the trustees/board members (hospital leadership, emergency services). Trustees/board members agreed with administrators on six of the top 10 factors $(60 \%$ agreement rate) and their agreement rate with physicians was $50 \%$ (five among the top 10 factors). These commonalties suggest a degree of agreement on the landscape of physician recruitment opportunities for their communities but also indicate some areas where there are differences of opinion regarding community capabilities. Trustee/board education retreats might be a forum for assessment and discussion of these similar and differing environmental views of these rural communities.

\subsection{Trustee/board member vs. hospital administrator}

Trustees/board members and administrators agreed on 6 of the top 10 factors important for their community to recruit physicians. There were no statistical differences across class metrics and only two differences noted in the individual factor analyses. Loan repayment was rated significantly higher by administrators versus trustee/board members. This may be an important difference as loan repayment has been identified as crucial to younger physicians as they leave medical school with large student loan debts. Trustee/board members may not appreciate the importance of this issue and may not support institutional efforts to deploy a loan repayment strategy in their physician recruitment efforts. This could lead to sub-optimal results, especially if the strategy is to recruit younger medical students with high debt. The other significant difference regards transfer arrangements. Transfer arrangements were rated higher by trustee/board members than for administrators. This may represent a relative lack of exposure to or appreciation of the transfer process, acuity or complexity of the patient care involved in transfer of patients outside the scope of care in the local facility, or other reasons. In any case, a frank discussion of these differences by trustees/board members might lead to better understanding of how these perceptions impact their community's ability to attract a productive physician workforce, the relationships between local and regional institutions and the complexities of providing comprehensive care in resource limited rural environments.

\subsection{Trustee/board member vs. hospital physician}

Trustees/board members and physicians agreed on five of the top 10 factors important for their community to recruit physicians. One class factor was significantly different, hospital/community support class. Trustee/board members rated this class higher than physicians. This difference might be a natural expression of living and working in a community and thus believing that the community is a supporting place for physicians. Interesting, physicians may not mirror these opinions, at least in the early years of living in these communities. There were four individual factors with statistically significant differences. First, physicians had higher scores for the factor teaching than trustee/board members. This may be an opportunity to support physicians in their desire to be involved in teaching while also training the next generation workforce for these rural facilities. Second, trustee/board member scores were higher for the factor administration than those scores for physicians. This finding suggests that 
physicians may be less inclined to take on additional administrative work than trustee/board members believe they are. It may also suggest that clinical care in rural areas requires most of a physician's focus. Third, trustee/board members had higher scores for the factor hospital sponsored CMEs than physicians. New technologies allow for an easier and more efficient method for accumulation of continuing education and the associated credits required for physicians to keep their license up to date. Lastly, trustee/board members rate welcome and recruitment programs higher than physicians. Communities use these types of programs to entice physicians to at least consider practicing in these areas and during the onboarding process. They are under the local control of trustee/board members in working with the CEO and administration. Thus, a clearer understanding of the gap between trustee/board members and physician could have significant impact in physician recruitment, performance and retention. Trustee/board members might also rate these welcome and recruitment programs highly since they have some degree of control over them.

\section{Conclusions}

This study has identified an interesting mix of commonalities and differences in how rural hospital trustee/board members and the administrators and physicians who work at their facilities view community strengths related to physician recruitment. Analyzing and discussing the areas of consensus and differences of opinion could help develop more effective physician recruitment strategies for these communities. Some of the factors identified in this study, such as loan repayment and welcome and recruitment programs, might be amenable to modifications that could lead to more effective and efficient use of valuable community resources. In addition, a follow-up study might be useful to ascertain what recruitment strategies were changed or added based on information provided by this research. Additional research is needed to ascertain whether these results from Iowa can be generalized to other rural communities. Furthermore, board education programs might be a useful vehicle to discuss how this type of information can be used to solve real world issues related to ensuring that rural communities have the physician resources necessary to improve health for their residents.

\section{CONFLICTS OF INTEREST Disclosure}

The authors declare they have no conflict of interest.

\section{REFERENCES}

[1] Thompson MJ, Lynge DC, Larson EH, et al. Characterizing the general surgery workforce in rural America. Archives of Surgery. 2005; 140 (1): 74-79. PMid: 15655209. https ://doi.org/10.1001/ar chsurg.140.1.74

[2] Health Resources \& Services Administration. Projecting the supply and demand for primary care practitioners through 2020. 2016. Available from: https://bhw.hrsa.gov/sites/default/files/b hw/nchwa/primarycarebrief.pdf

[3] Williams TE, Ellison EC. Population analysis predicts a future critical shortage of general surgeons. Surgery. 2008; 144: 548-56. PMid: 18847638. https ://doi.org/10.1016/j.surg.2008.05.019

[4] Belsky D, Ricketts T, Poley S, et al. Surgical deserts in the US: Places without surgeons. American College of Surgeons. 2009(2): 1-4

[5] Glasser M, Peters K, MacDowell M. Rural Illinois hospital chief executive officers' perceptions of provider shortages and issues in rural recruitment and retention. The Journal of Rural Health. 2006; 22(1): 59-62. PMid: 16441337. https://doi.org/10.1111/j. 1748-0361.2006.00007.x

[6] Latimer GE. Trustee: the basics of boards. Nursing Administration Quarterly. 2015; 30(1): 18-22. PMid: 25474661. https: //doi.org/10.1097/NAQ.0000000000000073

[7] Goeschel CA, Wachter RM, Pronovost PJ. Responsibility for quality improvement and patient safety: hospital board and medical staff leadership challenges. Chest. 2010; 138(1): 171-178. PMid: 20605815. https://doi.org/10.1378/chest.09-2051

Published by Sciedu Press
[8] Zusman E. Hospital boards changing with new challenges. Neurosurgery. 2012; 70(2): 16-17. PMid: 22251983. https://doi.org/ 10.1227/01.neu.0000410935.54076.01

[9] Tsai TC, Jha AK, Gawande AA, et al. Hospital board and management practices are strongly related to hospital performance on clinical quality metrics. Health Affairs. 2015; 34(8): 1304-1311. PMid: 26240243. https://doi.org/10.1377/hlthaff . 2014.1282

[10] Dunn P. Diversity on the rural hospital board: challenges for today and beyond. Trustee. 2007; 60(6): 12-16. PMid: 17608089.

[11] Probe R. The orthapaedist's role in healthcare system governance. Clinical Orthopaedics and Related Research. 2013; 471(6): 17841791. PMid: 23543420. https://doi.org/10.1007/s11999-0 13-2950-6

[12] Pate DC. Hospital-physician relations in a post-health care reform environment. The Journal of Legal Medicine. 2013; 33(1): 7-20. PMid: 22439705. https ://doi.org/10.1080/01947648.2012. 657595

[13] Cohn KH, Gill SL, Schwartz RW. Gaining hospital administrators' attention: Ways to improve physician-hospital management dialogue. Surgery. 2005; 137(2): 132-140. PMid: 15674192. https: //doi.org/10.1016/j.surg.2004.09.006

[14] Knecht PR, Bass K. Why board culture matters. Trustee. 2012; 65(5). PMid: 22693769.

[15] Samadi-Niya A. Suggested methods to improve physician-hospital relationships in Canada. Healthcare Management forum. 2015; 28(3): 106-113. PMid: 25850163. https ://doi.org/10.1177/084047 0415570169 
[16] Huff C. Done recruiting? Start retaining. Trustee Mag. 2014. Available from: http://www.trusteemag.com/articles/19-don e-recruiting-start-retaining

[17] Baker ET, Schmitz DF, Wasden SA, et al. Assessing Community Health Center (CHC) assets and capabilities for recruiting physicians: The CHC Community Apgar Questionnaire. Rural and Remote Health. 2012; 12: 2179. PMid: 23259832. Available from: http://www.rrh.org.au

[18] Reed A, Schmitz D, Baker E, et al. Assessment of factors for recruiting and retaining medical students to rural communities using the
Community Apgar Questionnaire. Family Medicine. 2017; 49(2): 132-136. PMid: 28218939.

[19] Schmitz DF, Baker E, Nukui A, et al. Idaho rural family physician workforce study: the Community Apgar Questionnaire. Rural and Remote Health. 2011; 11. PMid: 21790262. Available from: http://www.rrh.org. au

[20] Terry D, Baker E, Schmitz D. Community assets and capabilities to recruit and retain GPs: The Community Apgar Questionnaire in rural Victoria. Rural and Remote Health. 2016; 16: 3990. PMid: 27884056. Available from: http://www.rrh.org. au 